\title{
Ética, liberdade de expressão e discurso de ódio de gênero em sites de redes sociais
}

\author{
Luiz Peres-Neto \\ Escola Superior de Propaganda e Marketing, São Paulo, São Paulo, Brasil \\ Gabriela Agostinho Pereira \\ Escola Superior de Propaganda e Marketing, São Paulo, São Paulo, Brasil
}

\section{Resumo:}

O discurso de ódio e as questões de gênero representam uma temática fértil para a discussão sobre as dinâmicas comunicacionais e éticas nos sites de redes sociais. Este artigo busca: a) entender o que é o discurso de ódio de gênero e a sua midiatização; b) analisar como se dá a produção, circulação e o consumo desse tipo de discurso; e c) discutir os limites entre a liberdade de expressão e a defesa de valores democráticos. Para a elaboração desta pesquisa empírica, trabalhamos com quatro sites de redes sociais, sendo eles: Facebook, Instagram, Twitter e YouTube. Do ponto de vista metodológico, nos apoiamos na hermenêutica de profundidade proposta por J. B. Thompson. Identificamos, no corpus analisado, quatro tipos de discurso de ódio de gênero (machista, negacionista, homo/transfóbico e religioso) e que, nesses espaços, a midiatização dos discursos de ódio de gênero é percebida como simples opinião, desprovida de caráter ético e travestida de liberdade de expressão.

\section{Palavras-chave:}

Discurso de ódio. Ética. Gênero.

Liberdade de expressão.

\section{Introdução}

Este artigo propõe discutir o discurso de ódio motivado pelas questões de gênero nos sites de rede social Facebook, Instagram, Twitter e YouTube. Como problema de pesquisa, enseja duas questões: 1) Como surgem e se alimentam os discursos de ódio motivado pelas questões de gênero em contextos de midiatização nos sites de redes sociais? 2) Quais as causas e consequências éticas desse fenômeno para o reconhecimento da pluralidade e diversidade de gênero?

As discussões acerca das questões de gênero ganharam espaço na mídia e na agenda pública nos últimos anos, principalmente em Sites de Redes Sociais (SRS) ${ }^{1}$, uma vez que esses espaços permitem que, de alguma maneira, vozes até então silenciadas sejam potencialmente 
ouvidas. Dessa maneira, ademais de uma ampla penetração na sociedade ${ }^{2}$, diversos grupos e coletivos passaram a utilizar os SRS como um meio de mobilização e ativismo acerca das questões de gênero, questionando os padrões hegemônicos presentes na sociedade. Consideramos, assim, importante estudar as questões de gênero direcionando nosso olhar para os SRS por acreditarmos que esses são espaços midiáticos com características comunicacionais de produção e de consumo muito específicas e que diferem de outros formatos de mídia.

Os indivíduos que frequentam esses espaços têm a possibilidade não só de consumir, mas também de produzir, reproduzir e compartilhar conteúdos relacionados a praticamente todos os temas que lhes interessam (ou não) de maneira muito rápida, com um alcance potencialmente amplo e muitas vezes imensurável. Sendo assim, de acordo com o tipo de conteúdo produzido e consumido, esses sites podem tanto ser um espaço de transformação, que dá voz e visibilidade para pautas e pessoas que não o teriam fora daquele ambiente, quanto um espaço que reforça ideias hegemônicas, conservadoras ou discriminatórias.
Além disso, a maneira com a qual esses sites são utilizados não depende somente dos usuários e daquilo que eles querem publicar, postar, divulgar ou compartilhar. Essas plataformas são produzidas para serem consumidas de uma maneira específica e determinada pelos padrões e políticas de uso desses sites que, por sua vez, contam com uma lista de regras que define aquilo que pode ou não pode ser feito dentro de cada sRs. Neste trabalho, nos atentamos à esses padrões e políticas, uma vez que os consideramos interessantes do ponto de vista da comunicação, do consumo e da ética, no sentido de que afirmam contribuir e auxiliar na construção de um espaço dinâmico, democrático e que não tolera qualquer tipo de discriminação. Ao banirem determinado tipo de conteúdo e outros não, os próprios sites têm o poder de determinar quem tem espaço e quem não tem, quais assuntos são "legítimos" ou não.

Apesar da afirmação de preocupação com a manutenção de um espaço democrático, as possibilidades de uso e interação nos sRs permitiram que um fenômeno cultural e social preocupante do ponto de vista da construção

2 Os sites de redes sociais Facebook, Instagram, Youtube e Twitter contam, respectivamente, com 1,7 bilhões, 600 milhões, 1 bilhão e 319 milhões de usuários no mundo. Dados disponíveis em: <https://olhardigital.uol.com.br/ noticia/55-dos-brasileiros-acham-que-o-facebook-e-a-internet-diz-pesquisa/65422>; <http://g1.globo.com/tecnologia/ noticia/instagram-chega-a-600-milhoes-de-usuarios.ghtml/><https://www.youtube.com/yt/press/pt-BR/statistics. html/ http://www1.folha.uol.com.br/tec/2017/02/1861175-numero-de-usuarios-do-twitter-no-brasil-cresce-18em-2016.shtml>. Acesso em: 7 abr. 2017. 
de uma sociedade mais justa e igualitária ganhasse espaço e visibilidade: a figura do hater, ou seja, aquela pessoa que enuncia e prolifera discursos odiosos em relação a determinado assunto ou determinada pessoa. Esses haters são presença extensiva - e em certos espaços intensivas - ainda que de difícil mensuração. O objetivo dos haters nunca é debater ideias e/ou opiniões, mas ofender, intimidar e silenciar outros internautas que de alguma maneira fujam do padrão social hegemônico.

É importante apontar que, neste artigo, partimos da noção de que o discurso de ódio é motivado e direcionado para grupos sociais que fazem parte de minorias políticas (LEAL DA SILVA et al., 2011). Entendemos, portanto, o discurso de ódio como todo e qualquer discurso discriminatório e segregacionista com base em relações de poderes dicotômicos em que o indivíduo pertencente ao grupo social dominante externa tal discurso direcionando-o para um indivíduo pertencente a um grupo social oprimido. Seguimos a linha de autores como Waldron (2012), para quem, além do exposto, o discurso de ódio fere a dignidade da pessoa humana de grupos minoritários. Fazemos essa opção por acreditarmos que, do contrário, nos arriscaríamos a trabalhar com um conceito muito amplo que, empiricamente, poderia trazer dificuldades a este estudo. Ademais, este entendimento nos permitirá enfeixar a noção de discurso de ódio com as propostas teórico-metodológicas de Thompson (2011), para quem poder e dominação devem ser trabalhados analiticamente em consonância.

Esta visada sobre discurso de ódio não é a única. Mondal (2014), por exemplo, constrói um amplo debate sobre a liberdade de expressão e questões atinentes aos seus limites, como o discurso de ódio, a partir da problematização de controvérsias interculturais, deslindando como tais conflitos majoritariamente são tratados pela via jurídica e não pela sua dimensão ética e culturalista. Entendemos, no entanto, que não caberia neste artigo uma sistematização de todas - ou das principais - visadas teóricas sobre o discurso de ódio, algo já realizado por autores como Walker (1994) ou Herz e Molnar (2012) e que ensejaria uma outra proposta que escapa do escopo do presente texto. A despeito disso, ainda que de maneira abreviada, mais adiante, traçaremos um breve perfil sócio-histórico do conceito.

Consideramos importante pesquisar e estudar a construção e o efeito social dos discursos de ódio motivados pelas questões de gênero não só por acreditarmos que trata-se de uma discussão fundamental, que contribui para uma sociedade mais justa, mas também porque a noção de "papéis de gênero" está tão enraizada e naturalizada na sociedade que muitas vezes os próprios haters não 
conseguem enxergar a dimensão discriminatória e violenta do seu discurso, justificando suas produções discursivas com o argumento de que estão apenas emitindo uma opinião sobre o assunto, amparados pela noção liberal de liberdade de expressão.

\section{A construção da pesquisa}

Conforme detalhamos adiante, para a construção do corpus desta pesquisa optamos por focar em quatro sRs: Facebook, Instagram, Twitter e Youtube. Do ponto de vista teórico-metodológico, nos apoiamos na hermenêutica de profundidade proposta por Thompson (2011), uma vez que nos permite analisar as formas simbólicas acerca do discurso de ódio de gênero em sites de redes sociais e as maneiras como tais formas simbólicas mobilizam sentidos para a dominação e ainda sustentam relações de poder. Atentamos também para as consequências éticas desses discursos, pautados pela ideia da ética do reconhecimento e nas consequências sociais de não representar e reconhecer as pluralidades de gênero e suas subjetividades (FRASER, 2007). As análises realizadas foram, portanto, de corte qualitativo.

No que diz respeito especificamente ao recorte da amostra, nosso primeiro passo foi delimitar quais SRs a comporiam e a sua amplitude. Guiamos nossa escolha com base no número de usuários que cada um dos sRs supracitados possui e nas possibilidades de interação que eles oferecem. Um critério adotado no processo de construção da amostra foi o fato de os quatro sites permitirem que usuários reajam de alguma maneira (comentários, compartilhamentos, curtidas) em relação ao conteúdo publicado. Dentro deles, selecionamos a página da revista Carta Capital, o perfil da cantora Inês Brasil, o vídeo em comemoração ao Dia Internacional das Mulheres de 2016 da marca L'Oréal e as hashtags \#Feminazi e \#IdeologiaDeGênero, respectivamente. Optamos pela construção de uma amostra intencional. Como explicam Fragoso, Recuero e Amaral (2011, p.78), trata-se de um tipo de “amostras qualitativas, cujos elementos são selecionados conforme critérios que derivam do problema de pesquisa, das características do universo observado e das condições e métodos de observação e análise".

Assim sendo, para escolha do perfil da revista Carta Capital no Facebook partimos da premissa de que por ter um posicionamento mais ligado à política de esquerda e abordar em suas matérias diversos temas que podemos considerar contra-hegemônicos, encontraríamos, neste perfil, um espaço com diversas manifestações odiosas motivadas pelas questões de gênero nos comentários das publicações feitas pela revista. Trata-se, evidentemente, de uma pressuposição que fazemos a partir das observações feitas para a construção desta 
pesquisa. Além disso, supomos que o Facebook é um espaço utilizado não apenas como entretenimento, mas é também empregado pelas pessoas para se informar, como se a própria plataforma fosse um portal de notícias. De tal sorte, fez-nos sentido escolher um perfil de uma revista para analisarmos os discursos de ódio de gênero circunscritos a este ambiente. Como a revista aborda diversos outros assuntos que não necessariamente contemplam as questões de gênero, nosso primeiro passo foi recortar somente as publicações que exploravam esse tema. Dessa maneira, entramos na aba de publicações da página e digitamos no campo de busca a palavra "gênero" para que fosse possível visualizar todas as publicações feitas pela página que citavam essa palavra. Ao optarmos por fazer o recorte dessa maneira, entendemos que algumas publicações poderiam abordar as questões de gênero e não necessariamente citar a palavra gênero; nesses casos, tais publicações não entraram no nosso recorte. Ainda que limitador, esse foi o caminho que escolhemos para tornar esta pesquisa viável.

Ao nos depararmos com todas as publicações feitas pela página que citavam a palavra gênero, encontramos como desafio o volume de conteúdo para ser analisado, uma vez que o resultado da busca contemplava todas as publicações que citam a palavra gênero feitas no Facebook pela revista Carta Capital.
Optamos, então, por realizar um último recorte e, assim, escolhemos as 10 últimas publicações que apareceram no nosso resultado de busca. É importante destacar que esse recorte foi feito no dia 17 de maio de 2017 , razão pela qual foram recortadas as 10 últimas publicações feitas antes dessa data.

No Instagram encontramos os mesmos desafios do Facebook em relação ao volume de conteúdo disponível. Assim, para o recorte da amostra no Instagram, levamos em consideração o fato de que a plataforma é um site de rede social focado em perfis pessoais de personalidades, celebridades e pessoas públicas que postam fotos/imagens/vídeos do seu cotidiano, razão pela qual optamos pela escolha de um perfil de uma personalidade. Porém, existem milhares de personalidades/ celebridades presentes na plataforma. Dessa maneira, outro critério foi considerado para a construção do nosso recorte: as questões de gênero, ou seja, era preciso escolher o perfil de alguma personalidade/celebridade que de alguma maneira abordasse as questões de gênero. Optamos, então, centrar esta pesquisa no perfil da cantora Inês Brasil.

Inês é uma mulher negra, sem educação formal e que é frequentemente confundida com uma travesti pela sua aparência física e pela maneira como se comporta, considerada vulgar por muitas pessoas, já que publica 
com frequência fotos seminuas e com apelo sexual na plataforma. O perfil da cantora no Instagram conta com mais de 535 mil seguidores e nossa escolha se deu pelo fato de Inês ser uma mulher que foge completamente do que é esperado de uma mulher na sociedade. A cantora não aborda diretamente as questões de gênero, não é uma militante em relação à temática e não faz publicações a respeito do tema. No entanto, a maneira como vive e como se comporta está estreitamente relacionada com essas questões. Neste caso, também sentimos a necessidade de aprofundar ainda mais nosso recorte, uma vez que a cantora já publicou mais de 3.400 fotos e vídeos na plataforma. Dessa maneira, escolhemos recortar todas as publicações feitas (no total, 14 posts) em datas próximas a um acontecimento envolvendo a cantora, ocorrido no final de março de 2017, quando Inês fez um show na cidade de Manaus e acabou se masturbando com o microfone em cima do palco, gerando muita polêmica e críticas até mesmo por parte dos seus fãs, que consideraram que a cantora havia "passado dos limites".

Por seu turno, o processo de recorte da amostra do YouTube foi muito semelhante ao realizado nos casos do Facebook e Instagram, ou seja, partimos da premissa de que, ao optar por um conteúdo que abordasse as questões de gênero e por esta temática ser vista como um "tabu" na sociedade, comentários odiosos em relação ao tema seriam encontrados na publicação. Assim, optamos por analisar a propaganda do Dia Internacional das Mulheres de 2016 veiculada pela marca de cosméticos L'Óreal Paris no YouTube. Também consideramos interessante escolher um vídeo produzido por uma marca e não um canal de alguma celebridade, por exemplo, para entender de que maneira algumas marcas/empresas estão se posicionando em relação ao tema das questões de gênero, como o fazem e a recepção dos mesmos nos sites de rede sociais.

A campanha escolhida conta com a presença da modelo transgênera ${ }^{3}$ Valentina Sampaio. Nela, Valentina fala sobre estar comemorado seu primeiro dia das mulheres "oficial" e mostra, em um vídeo publicitário, seu documento de identidade com seu nome, o que supomos que faria com que alguns internautas fizessem comentários odiosos em razão da escolha da marca em homenagear uma mulher transgênera. mostra para a sociedade como mulher através de seus gestos, falas e atos. Logo, apesar de reconhecer que 0 "a" no final pode trazer implícito dicotomias de gênero que objetivam feminizar, entendemos que nesse caso o uso é apropriado devido ao histórico de luta de Valentina Sampaio para ser reconhecida como a mulher que é. 
É importante ressaltar que a escolha de Valentina como protagonista não foi um acaso. Não há dúvidas de que a marca foi inovadora em sua abordagem dando visibilidade para as mulheres transgêneras que, como sabemos, têm muito pouco (ou nenhum) espaço na mídia. Porém, fizeram questão de escolher uma mulher transgênera que poderia ser "aceita" com mais facilidade pelo público. Do ponto de vista da representatividade, a modelo se encaixa perfeitamente em todos os padrões de beleza impostos pela sociedade: é alta, magra, tem cabelos lisos e claros, pele branca e uma aparência delicada. É a personificação de tudo que é esperado da feminilidade e não representa a realidade de boa parte das mulheres.

Por fim, como o Twitter é uma plataforma que funciona de uma maneira diferente dos outros três SRS anteriormente mencionados, especificamente por não ser possível analisarmos uma determinada publicação e vermos os comentários feitos, optamos por fazer nosso recorte com base em hashtags, ferramenta muito utilizada no Twitter e que permite rastrear todas as publicações feitas no site que utilizam uma determinada hashtag. Assim, escolhemos recortar as publicações que citam as hashtags \#Feminazi e \#IdeologiaDeGênero, por acreditarmos que poderiam estar acompanhadas de discursos odiosos, já que elas são frequentemente utilizadas para fazer críticas a qualquer manifestação de igualdade em relação às questões de gênero.

No que diz respeito a \#IdeologiaDeGênero, trata-se de uma hashtag frequentemente utilizada para falar sobre gênero, criticando o questionamento de sua binaridade, constituindo-se como uma disputa de poder contrária à visão de que os gêneros são construções sociais. Em síntese, vislumbramos nela uma forma de mobilização de sentidos para a dominação, definição de ideologia proposta por John B. Thompson (2001), e não uma forma de promover igualdade e respeito entre as pessoas que fogem do padrão binário e o questionam. Já a \#Feminazi é, por si só, uma manifestação odiosa por comparar um movimento que luta pela equidade de gêneros com algo tão violento e ditatorial quanto o nazismo.

Ao fazermos a busca por essas hashtags no Twitter, nos deparamos com o mesmo desafio que encontramos no Facebook e no Instagram: o imenso volume de conteúdo disponível. Optamos, então, por usar o filtro de busca avançado disponibilizado pelo próprio Twitter e restringir a busca somente para publicações que estavam em português, já que muitas apareciam em espanhol. Como o número de publicações que apareceram como resultado ainda era muito alto, decidimos, ademais, fazer um recorte temporal, sendo assim, 
ficamos apenas com as publicações em português que citavam as hashtags \#IdeologiaDeGênero e \#Feminazi entre o1 de janeiro e 17 de maio de 2017.

Em relação à análise, conforme mencionado anteriormente, decidimos apoiar-nos na Hermenêutica de Profundidade (HP) proposta por J. B. Thompson (2011). Esse autor a propõe como referencial teórico-metodológico em seu livro Ideologia e Cultura Moderna para analisar fenômenos culturais. Optamos por essa proposta ao assumirmos que os discursos de ódio de gênero em SRS são fenômenos culturais, ou seja, um conjunto de formas simbólicas presentes em contextos socioculturais estruturados (THOMPSON, 2011). Entendemos que a HP permite que contemplemos não só os discursos e os mecanismos dos sites de redes sociais, mas também os contextos sociais e culturais em que se encontram.

As formas simbólicas são definidas por Thompson (2011, p. 79) como "um amplo espectro de ações e falas, imagens e textos, que são produzidos por sujeitos e reconhecidos por eles e outros como construtos significativos." Assim, as formas simbólicas acerca das questões de gênero e, mais especificamente, sobre a discriminação de gênero, são constitutivas do fenômeno cultural do discurso de ódio de gênero em SRS. É importante destacar que a nossa pesquisa se concentra especificamente no discurso de ódio motivado pelas questões de gênero em contextos midiatizados e publicizados dos SRS. Podemos afirmar, então, que esse tipo de discurso é de fato um fenômeno cultural (dentro da teoria proposta por Thompson), no sentido de que essas formas simbólicas fazem parte de um contexto social e cultural que constituem determinado sentido para elas e também implicam relações de poder e de conflito.

Para a realização da análise das formas simbólicas, Thompson (2011) compreende que são necessários três procedimentos iniciais "[...] que não são parte de um método sequencial, mas sim dimensões analíticas distintas de um processo interpretativo complexo." (p.365). As três fases são: a) análise sócio-histórica, que objetiva reconstruir as condições sociais e históricas de produção, circulação e recepção das formas simbólicas; b)análise formal ou discursiva, que foca na organização interna das formas simbólicas, suas características estruturais e padrões; c) a interpretação/re-interpretação, que contempla uma construção criativa de possibilidades de significados das formas simbólicas.

\section{Gênero, ética e discurso de ódio: reflexões para além do reconhecimento}

Não é possível falarmos sobre o discurso de ódio sem situarmos o contexto no qual a expressão surgiu. Segundo Walker (1994), 
as questões envolvendo o "hate speech" aparecem nos anos 1920 nos Estados Unidos e estão fortemente ligadas à questão racial. A década de 1920 marcou as primeiras discussões políticas e legais acerca da restrição de discursos ofensivos ligados à raça e religião. Walker (1994) afirma que, no que diz respeito a essas discussões, dois grupos se opunham naquele momento, a União Americana das Liberdades Civis (UALC), criada na referida década com o intuito de encampar a defesa liberal do direito à liberdade de expressão, e um conjunto de coletivos que historicamente sofria com o preconceito e as mais diversas formas de discriminação racial, étnica e religiosa. "Do choque dessas duas forças organizacionais, a questão do discurso de ódio nasceu” (p. 9-10)

Evidentemente, é preciso matizar o fato de apontarmos o surgimento do discurso de ódio nos Estados Unidos da América do Norte (EUA), no século XX. É evidente que ele existe antes de tal marco temporal e também em outros países e contextos. No entanto, como argumentam Walker (1994) e Price (2015), dado a posição privilegiada que a liberdade de expressão goza nos EUA, como um dos pilares de sua arquitetura constitucional e democrática, além de graves feridas raciais, étnicas e religiosas, favoreceu o florescimento nesse país um rico debate sobre o discurso de ódio e os limites da liberdade de expressão.

Como é de amplo conhecimento nos estudos sobre comunicação e direito, a Primeira Emenda da Constituição dos EUA, aprovada em 1791, protege, entre outras coisas, a liberdade de expressão (PRICE, 2015). Porém, apenas entre os anos 1920 e 1970, respectivamente, a Suprema Corte daquele país passou a alongar essa proteção (da liberdade de expressão), forjando o entendimento de que qualquer manifestação de conteúdo é valorosa para a democracia e, por isso, merece ser respeitada, seja qual for o conteúdo. Ou seja, o discurso de ódio proferido contra negros, mulheres e homossexuais, por exemplo, ainda que de maneira indireta, é protegido nos EUA pela interpretação ampla da Lei, uma vez que predomina a doutrina de que limitar esses discursos seria uma afronta ao direito individual da liberdade de expressão e, consequentemente, à democracia (SILVA, 2014; CARLSSON, 2016).

A liberdade de expressão nos EUA é extremamente protegida e se sobrepõe a outros direitos como, por exemplo, o direito à privacidade e à igualdade. A mera permissividade de marchas nazistas ou de ideologias supremacistas, 
que ocorrem frequentemente nos EUA, representa não só uma grande violência, mas também reforça e legitima discriminações que vão contra o princípio ético e político de igualdade. Por essa razão, Silva (2014) afirma que a liberdade de expressão no contexto norte-americano goza de certa imunidade devido à abertura política que afiança tal direito.

Já no Brasil, a abordagem a respeito do discurso de ódio difere da maneira como é feita nos EUA. Um dos casos mais famosos acerca do discurso de ódio no país é o de Siegfried Ellwanger Castran, que publicou diversos livros antissemitas nos quais negava o Holocausto. Ao analisar a atuação do Supremo Tribunal Federal (STF) nesse caso, Sarmento (2006) afirma que o caso Ellwanger é "qualificado por integrantes da Corte como o mais relevante julgado da história daquele tribunal em matéria de direitos humanos" (p. 3). No seu julgamento, foi decidido que a liberdade de expressão não protege manifestações antissemitas, podendo ser consideradas crime de racismo. Ou seja, no Brasil, sentou-se a jurisprudência similar a outros países, em grande medida que seguem a interpretação europeia, segundo a qual é possível colocar limites à liberdade de expressão, uma vez que a dignidade humana se sobrepõe a ela.

É importante ressaltarmos aqui a complexidade que requerem as discussões acerca da liberdade de expressão e do discurso de ódio. Por mais que pareça óbvio que proteger constitucionalmente o exercício do discurso de ódio - como no contexto dos EUA - não seria ético na medida em que, quando esse tipo de discurso é direcionado para minorias políticas como negros, mulheres e LGBTS, por exemplo, reforça as assimetrias sociais e de poder, contribuindo para a manutenção e legitimação do preconceito, limitar ou proibir determinados discursos em razão do seu conteúdo pode abrir brechas para que a liberdade de expressão seja reprimida de maneira extrema, como já vivido no Brasil em períodos ditatoriais, o que tampouco tem qualquer fundamentação ética que a ampare. Não há literatura que proponha uma solução magistral para essa questão e não é nossa pretensão propô-la neste artigo. Não obstante, o que queremos neste trabalho é levantar discussões acerca da temática levando em consideração os pontos de vista social, comunicacional e ético.

Portanto, é necessário esclarecer que, neste artigo, apesar de reconhecer a nocividade do discurso de ódio de oposições, que pode estar relacionado não necessariamente às minorias políticas, nosso foco reside no discurso de ódio direcionado às minorias políticas, especialmente aquelas ligadas às questões de gênero. Nosso entendimento está filiado a definição para o conceito de discurso de ódio feita por Leal da Silva et al. (2011) para quem não se 
pode confundir o discurso de ódio com a liberdade de pensamento. O primeiro, requer uma manifestação, ou seja, a passagem do plano abstrato ao fático. Ademais, o discurso de ódio "[...]é uma manifestação segregacionista, baseada na dicotomia superior (emissor) e inferior (atingido) e, como manifestação que é, passa a existir quando é dada a conhecer por outrem que não o próprio autor começando pela externalidade." (p.447).

Nesse sentido, ao falarmos do discurso de ódio de gênero, estamos falando de um discurso ideológico, dado que ele mobiliza sentidos para a manutenção do poder e de suas relações desiguais. Entendemos, consequentemente, que todo discurso de ódio é necessariamente antiético, ou seja, contrário ao bem comum e ao ideal de justiça, já que reforça posturas discriminatórias. Como bem explica a filósofa espanhola Adela Cortina (2009), a despeito das distintas propostas que os paradigmas morais oferecem, poderíamos encontrar um mínimo denominador comum à ética, priorizando o plano normativo (ideal de justiça) ante o debate sobre a vida feliz (bem comum), eixos epistêmicos pelos quais navegam as propostas éticas. Tal ética mínima pressupõe "o repúdio universal à tortura, à exploração e à calúnia" (p. 32). Destarte, entendemos como insustentável a defesa ética do discurso de ódio, ainda que em prol da liberdade de expressão.
Importa apontar que a nossa abordagem do conceito de gênero tem como base o pensamento da filósofa Judith Butler (2016), ou seja, entendemos o gênero como um ato performativo intencional que produz efeitos e significados.

Butler (2016) abre espaço para pensarmos o gênero além da dualidade masculino/feminino, macho/fêmea. A autora problematiza a ideia de que o sexo, por ser biológico, é natural e o gênero é socialmente construído. Sabemos que o determinismo biológico do sexo tem a função de naturalizar a desigualdade entre homens e mulheres. Claro está que essa naturalização da desigualdade objetiva assegurar o poder social e político da figura masculina, traço marcante das culturas patriarcais. Porém, para Butler (2016), não só a ideia do sexo é determinista, mas também a noção do gênero culturalmente construído, uma vez que sugere um certo determinismo de significados de gênero.

Butler (2016, p. 29) argumenta que “[...] não há como recorrer a um corpo que já não tenha sido sempre interpretado por meio de significados culturais." O que significa dizer que o corpo é desde sempre significado através dos discursos que circulam ao seu redor. Ao afirmar, antes mesmo de nascer, que aquele bebê é uma menina, por exemplo, são acionados diversos discursos 
culturais sobre o que é ser uma menina e uma expectativa é construída em relação à vida da criança. Assim, Butler (2016) argumenta que tanto o sexo quanto o gênero são culturais e discursivos, logo não é possível afirmar que o sexo é natural.

Além disso, é necessário ressaltar que as significações sociais e culturais dadas ao sexo/ gênero são problemáticas também no que diz respeito à promoção de uma sociedade democrática, posto que essas significações compreendem um sistema binário de gênero e sexo que responde à uma heteronormatividade compulsória (BUTLER, 2016), que não reflete nem representa de maneira alguma a multiplicidade dos sujeitos.

Existe um modelo de feminilidade e masculinidade que são considerados adequados para a manutenção da heteronormatividade. Esse modelo é um regime de poder que exclui sujeitos e identidades com configurações de sexo, gênero e práticas sexuais que diferem do modelo estabelecido. A transexualidade é um (entre diversos) exemplo de subversão do modelo heteronormativo e da ordem compulsória entre sexo/gênero/prática sexual (BUTLER, 2016). Pessoas transexuais são a prova de que os sistemas binários e suas normatizações e arbitrariedade são incapazes de contemplar as diversas subjetividades. A construção sociocultural tanto de gênero quanto de sexo é problemática justamente por não permitir o desenvolvimento das subjetividades.

Logo, se o sexo/gênero é uma forma primária de significar as relações de poder na sociedade e existe uma assimetria e desigualdade nessas relações de poder, podemos afirmar que a violência estrutural, social, cultural, política e biológica praticada contra os sujeitos que subvertem o modelo e ordem impostos é tremenda. Isso porque ela reside na invisibilidade e no não reconhecimento dos sujeitos, reprimindo-os de qualquer possibilidade de atuação social e política, algo que Fraser (2007) acredita ser antiético, na medida em que o reconhecimento é necessário para que os sujeitos participem igualmente dessas duas esferas.

Ainda que possamos matizar elementos qualitativos, cabe ressaltar que nos últimos anos as questões de gênero em sua totalidade passaram a ter maior visibilidade tanto na mídia tradicional como nos sites de redes sociais (SARMENTO, 2017). A visibilidade que os sites de redes sociais promovem para os discursos contra-hegemônicos é de extrema importância porque tenciona as relações de poder existentes, ao passo que todos (ou quase todos) ali presentes têm a chance de se manifestar, ainda que limitados pela mediação de um algoritmo. Dessa 
maneira, os sites de redes sociais se configuram como espaços onde há a representatividade de sujeitos pertencentes a grupos sociais politicamente minoritários, como é o caso das mulheres e da comunidade LGBTS.

Porém, não podemos deixar de atentar que, apesar de serem espaços potencialmente mais democráticos devido à visibilidade e representatividade dos sujeitos em relação aos questionamentos de gênero, Fraser (2007) argumenta que essa representatividade é insuficiente para promover uma mudança social significativa. Para essa autora, estratégias de reconhecimento e representação são importantes, porém estão em uma dimensão simbólica que não contribuem per se para diminuir desigualdades.

Fraser (2007) afirma que devemos nos preocupar com as concepções de justiça na sociedade, sendo necessária uma justiça social que não exija somente estratégias de reconhecimento e representação, mas também estratégias de redistribuição, que pensem as questões materiais derivadas da diferenciação entre classes sociais e gênero como a redistribuição de renda, de recursos e de oportunidades. Dessa maneira, no entendimento de Fraser (2007), apesar de serem questões importantes, não basta que mulheres, transexuais, travestis e lésbicas, por exemplo, sejam representados e reconhecidos; é preciso ir além e, desta maneira, fazer com que essas pessoas tenham também acesso à educação, emprego, renda e oportunidade em condições de igualdade.

Pela via de uma ética material fundada na experiência social, Nancy Fraser (2007) propõe um modelo de justiça social que combina a justiça redistributiva e a justiça de reconhecimento, propondo uma análise alternativa à teoria do reconhecimento. Aqui nos distanciamos, por exemplo, de autores vinculado mais diretamente a Axel Honnet (2006) e sua proposta de reconhecimento. Sem lugar a dúvidas, um caminho profícuo para as pesquisas em comunicação política, como as de Maia (2014). Porém, aleijadas da visada aqui articulada, uma vez que entendemos ser essencial para o debate do discurso de ódio de gênero propostas éticas que unam redistribuição e reconhecimento.

A sagacidade da teoria "fraseriana" permite aproximar paradigmas até então vistos como opostos. Por um lado, propõe não abandonar o reconhecimento, entendendo-o como categoria moral e, situando-o como necessário na medida em que a sociedade, ao não reconhecer determinados sujeitos, os tornam invisíveis; não obstante, por outro lado, Fraser (2007) vislumbra os limites do reconhecimento e o conjuga com a noção de redistribuição, paradigma moral que por muito tempo ignorou a visada do reconhecimento. 
Nesse sentido, tomando a noção de reconhecimento, o discurso de ódio de gênero pode ser considerado uma forma de não reconhecimento ao não tratar e não reconhecer mulheres transexuais como mulheres ou casais do mesmo sexo como uma família, por exemplo. Ao não serem reconhecidos, esses sujeitos são impedidos de participar ativamente da vida social e da esfera pública, na medida em que suas reivindicações não são contempladas.

Assim, entendemos ser importante pensarmos a questão do discurso de ódio de gênero em sites de redes sociais através de uma dimensão da ética do reconhecimento e da redistribuição, pois esses discursos contribuem para o não reconhecimento dos sujeitos que subvertem a ordem compulsória da heteronormatividade, por isso, fazem com que esses sujeitos não só deixem de construir uma imagem positiva de si, já que não há o reconhecimento do outro, mas também, sejam impedidos de participar ativamente e em igualdade na sociedade e sofram as consequências de relações assimétricas de poder, razão pela qual a proposta de Fraser (2007) nos permite pensar o discurso de ódio de gênero pelas lentes de uma teoria da justiça do reconhecimento e da redistribuição.

\section{Comunicação mediada por computador, midiatização e discurso de ódio}

No campo da comunicação já é exaustiva a afirmação de que os meios de comunicação, cada qual ao seu tempo, provocaram profunda mudança social, cultural, comportamental e política (BRIGGS; BURKE, 2005). No caso específico da Comunicação Mediada pelo Computador, Recuero (2014) afirma que o advento tecnológico mudou radicalmente as maneiras de organização, identidade, mobilização e expressão. Em síntese, pode-se considerar difusa a divisão entre produtor, transmissor e receptor, muito especialmente nos SRS, uma vez que um único indivíduo pode desempenhar todas essas funções ao mesmo tempo.

Ao falar sobre o contexto comunicacional contemporâneo, o sociólogo espanhol Manuel Castells (2013) nos ajuda a problematizar os traços característico da comunicação em rede ao nos apresentar o conceito de Mass Self-Communication. Para Castells (2013), esse novo modelo comunicacional corresponde a todo e qualquer conteúdo (imagens, vídeos, textos, discursos) que possa ser produzido e distribuído por qualquer indivíduo que utilize a internet. Castells (2013, p. 16) afirma que a Mass Self-Communication "fornece a plataforma tecnológica para a autonomia do ator social, seja ele individual ou coletivo, em relação às instituições da sociedade". 
No entanto, é importante destacarmos que Castells (2013) não previu o efeito que os algoritmos utilizados nos SRS poderiam ter em relação à experiência e usabilidade do usuário. Utilizando como exemplo somente o Facebook, Pereira (2016) nos mostra que com base nos nossos interesses e comportamentos na plataforma, o site delimita o conteúdo que considera mais relevante para cada usuário. A consequência é uma linha do tempo que só nos mostra aquilo que o sRs deduz que queremos ver. Ou seja, ao priorizar a exibição de conteúdos com os quais seus usuários tem mais afinidade e são mais propensos à interação, o Facebook contribui para a construção de uma linha do tempo personalizada para cada usuário, visibilizando aquilo que o algoritmo da plataforma acredita que seus usuários queiram ver com base nas interações que fazem.

Os cálculos algorítmicos, ao privilegiarem a conexão entre atores com laços fortes, contribui para a formação de "bolhas" políticas, sociais e culturais. Se tudo que vemos na plataforma é conteúdo com o qual concordamos, tendemos a acreditar que tudo o que pensamos e fazemos é o correto. Ao priorizar conteúdos que mobilizam mais interações entre os usuários e a visibilidade entre usuários com maior interação entre si, passa-se a impressão de que as opiniões presentes nas plataformas representam a opinião da maioria, persuadindo a adesão ou reafirmação de determinada opinião e contribuindo para a polarização de ideias.

Castells (2005), com efeito, argumenta que a internet "é um instrumento que desenvolve, mas que não muda os comportamentos; ao contrário, os comportamentos apropriam-se da internet, amplificam-se e potencializam-se a partir do que são". (idem, p. 272). Neste sentido, é possível afirmar que o discurso de ódio não passou a existir com o advento da internet e dos sites de redes sociais, mas sim foi potencializado - e amplificado - a partir deles.

Ademais, é importante ressaltar que a presença do discurso de ódio nas mídias não é uma exclusividade dos sites de redes sociais. Sabemos que os meios de comunicação como um todo são carregados de discursos, ideologias e são também parte - ainda que não exclusiva - do processo de produção, circulação e consumo de discursos de ódio. Nossa atenção reside, no entanto, nos SRS por uma questão de recorte.

Partindo destes pressupostos, entendemos que os discursos ideológicos dominantes nos sites de redes sociais em relação às questões de gênero servem para manter relações de poder assimétricas estabelecidas por uma sociedade conservadora, machista e patriarcal. Tais discursos estão imersos em uma lógica de midiatização 
Dadas as diferentes aproximações ao conceito de midiatização, ainda que de maneira abreviada, faz-se necessário uma breve explanação sobre qual apropriação fazemos dele. Para Gomes (2016), a sociedade em midiatização "é um novo modo de ser no mundo, pelo qual os meios não mais são utilizados como instrumentos possibilitadores das relações pessoais, mas fazem parte da autocompreensão social e individual" (p.19), ou seja, a identidade do sujeito é construída através de sua interação com os meios, que por sua vez, são instrumentos tecnológicos de comunicação.

O discurso de ódio de gênero midiatizado que abordamos neste trabalho é um modelo discursivo específico e, de alguma maneira, exclusivo dos sites de redes sociais e de contextos de digitalização da cultura. Assim, entendemos que os discursos de ódio motivados pelas questões de gênero em sites de redes sociais caracterizam-se como discursos de ódio midiatizado não só pela sua presença em uma mídia, mas por estarem estruturados em um contexto no qual o sujeito constrói sua identidade a partir da interação com essa mídia, o que significa que, proferir/consumir esse tipo de discurso é, em maior ou menor escala, um ato revelador e confirmador de identidades.

É importante destacar também que tais ideias (comunicação, discursos de ódio, questões de gênero, relações de poder e ideologias) operam dentro de uma lógica do consumo, que é compreendida por nós como "um dos indicadores mais efetivos das práticas socioculturais e do imaginário de uma sociedade" (BACCEGA, 2010).

Assim, entendemos que o estudo do consumo e da produção de discursos de ódio de gênero nos sites de redes sociais é também relevante na medida em que consumir e/ou produzir determinado tipo de discurso é também uma revelação e determinação do lugar que esses sujeitos ocupam na hierarquia social e o poder que exercem na sociedade. Trata-se de um importante fator para pensar os processos de construção de cidadania.

Com efeito, para Canclini (2010), consumo e cidadania se conectam na medida em que as maneiras pelas quais consumimos afetam os modos pelas quais exercemos a cidadania. $E$, se partimos do entendimento de que a cidadania considera tanto as questões de direitos e deveres dos cidadãos quanto políticas de reconhecimento, o consumo de discursos odiosos pode impedir que os sujeitos que são alvo dessa forma de discriminação exerçam sua cidadania de maneira plena, submetendo-os a processos de exclusão social.

\section{Análises e considerações em progresso}

No início deste trabalho mencionamos que nosso problema de pesquisa enseja duas 
questões: como surgem e se alimentam os discursos de ódio motivado pelas questões de gênero em contextos de midiatização, especificamente nos sites de redes sociais? Quais as causas e consequências éticas desse fenômeno para o reconhecimento da pluralidade e diversidade de gênero? É importante relembrarmos que, neste artigo, consideramos como discurso de ódio de gênero não apenas discursos que incitam o ódio ou a violência, mas todos os tipos de discursos discriminatórios e segregacionistas que são proferidos contra aqueles indivíduos que pertencem a grupos sociais politicamente minoritários em razão de questões de gênero. Entendemos também que o discurso de ódio é um discurso ideológico visto que mobiliza sentidos para a manutenção do poder e de suas relações desiguais (THOMPSON, 2011). Logo, todos os discursos que foram classificados como negativos na pesquisa feita nos sites Facebook, Instagram, YouTube e Twitter, são considerados por nós discursos odiosos, uma vez que discriminam indivíduos em razão das questões de gênero, mesmo que não incitem o ódio ou a violência.

Assim, no que diz respeito à frequência desses discursos odiosos motivados por questões de gênero nos sites de redes sociais pesquisados, observamos que eles são menos frequentes na amostra do que supúnhamos. Somando os quatro sites pesquisados, nossa amostra conta com 4.793 comentários, dos quais 1.107 foram classificados como negativos, ou seja, considerados discursos odiosos motivados por questões de gênero, o que representa $23 \%$ do total de comentários analisados.

Apesar do número de comentários odiosos na amostra ser menor do que imaginávamos, é importante ressaltar que independentemente da frequência com que eles aparecem, sua nocividade é a mesma, visto que não reconhecem a pluralidade de gênero e como já mencionado anteriormente, o reconhecimento é necessário tanto para que os sujeitos possam participar em igualdade da vida social e política (FRASER, 2007). Ou seja, é preciso pensar nesses discursos odiosos a partir de uma perspectiva da ética do reconhecimento.

Entendemos que as limitações à extensão deste artigo nos impedem de reproduzir e ilustrar as análises realizadas que podem, contudo, serem consultadas em PEREIRA (2018). Não obstante, consideramos interessante apresentar um exemplo que possa ilustrar uma das maneiras pelas quais o discurso de ódio de gênero é manifestado nos sites de redes sociais.

Uma das publicações recortadas na amostra abordava o tema da discussão de gênero dentro das escolas. Nela, foi encontrado 
o seguinte comentário feito por um internauta: "Não tem o que se discutir Homem é homem, mulheré mulher e macaco é macaco"s. No exemplo, é muito claro o não reconhecimento de todos os sujeitos que subvertem a ordem compulsória da heteronormatividade e também a imposição social para que as pessoas se adequem ao que esse sistema binário propõe, que é exatamente o que está registrado no comentário, ou seja, homem é homem, mulher é mulher, e tudo que foge desse entendimento deve ser invisibilizado e marginalizado.

Quando o autor do comentário afirma que "não tem o que se discutir", ele evidencia que essa lógica de certo e errado que está profundamente enraizada na sociedade, na qual o certo são as pessoas que se seguem os ideais de feminilidade e masculinidade que sustentam a heteronormatividade compulsória, e o errado são todos os outros sujeitos em suas diversas subjetividades. Além disso, ao afirmar que assim como mulher é mulher e homem é homem, o macaco é macaco, ele evidencia o peso que o fator biológico exerce na percepção que algumas pessoas têm no que concerne às questões de gênero. Para elas, assim como os macacos, os seres humanos são animais e, como animais, só podem ser classificados de duas maneiras: fêmea e macho. Outro ponto importante é que, ao afirmar que "não tem o que se discutir", o autor do comentário pressupõe que a opinião dele é a única correta e evidência que não está aberto para questionamentos. Logo, se não há questionamento, não há espaço para que sujeitos subversivos existam, e, como abordamos anteriormente, é importante pensar as questões de gênero através de uma dimensão ética do reconhecimento (FRASER, 2007), na medida em que a invisibilidade desses sujeitos os impede de participar ativamente e em igualdade na sociedade.

Nas análises foi possível observar que os discursos de ódio de gênero midiatizados nos sites de redes sociais são de fato discursos naturalizados, que são percebidos como simples 'opiniões' e não como formas de preconceito e discriminação. Quatro tipologias dos discursos de ódio acerca dessa temática foram observadas em nossa amostra, conforme exposto na Figura 1.

Assim, afirmamos que os sentidos mobilizados pelas formas simbólicas em torno das questões de gênero operam no sentido 
de sustentar as relações de dominação de gênero através de discursos discriminatórios que estão naturalizados na sociedade como aqueles que afirmam que mulheres devem se comportar de determinada maneira, discursos que justificam o preconceito através de fatores biológicos - como se estes fossem inquestionáveis -, discursos de ódio contra pessoas que não se reconhecem na binariedade de sexo e gênero e discursos que militam contra a discussão de gênero em razão de preceitos religiosos que são manifestados através do que denominam de valores morais e religiosos.

Figura 1: Tipologias do discurso de ódio de gênero na amostra

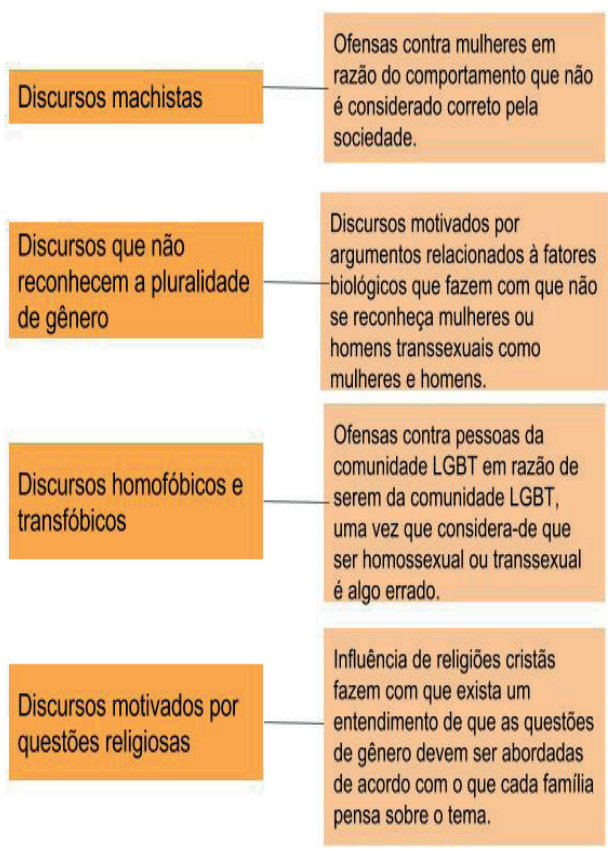

Fonte: Elaboração própria (2018).

Observamos que as discriminações de gênero históricas na sociedade contribuem de uma maneira muito significativa para que tais discursos sejam naturalizados, o que é explicado por Bourdieu (1998) através do conceito de poder simbólico. Os preconceitos são passados de geração em geração e são dados como algo normal, natural, o que faz com que as pessoas não questionem os motivos que as levam pensar de determinada maneira ou ter determinada opinião. Não há a consciência de que o machismo, homofobia e a transfobia, por exemplo, são construções sociais e como 
toda construção, podem ser desconstruídas e questionadas.

Também observamos que os sites de redes sociais pesquisados contribuem para que esses discursos sejam manifestados em suas plataformas visto que, apesar de terem políticas de privacidade e padrões de uso que afirmam não tolerar o discurso de ódio, os mesmos entendem como discursos odiosos apenas aqueles que incitam o ódio ou a violência em casos muito limitados. Isso porque assumem uma postura relativista, afirmando que o que pode ser considerado ofensivo para uma pessoa poderia não ser para outra e, nesses casos, esses discursos deveriam ser tolerados, assumindo o modelo de liberade de expressão dos EUA como norma, universalizando-o, desconsiderando o caráter global e transnacional dos SRs.

Dentre os SRS analisados, a única exceção observada em relação às políticas e padrões de uso é o Twitter, que afirma reconhecer que discursos odiosos são aqueles que silenciam o outro e não apenas aqueles que incitam o ódio ou a violência. Porém, a despeito de se posicionar dessa maneira, também foram encontrados discursos odiosos nessa plataforma, o que evidencia que não há de fato um controle por parte dos sites de redes sociais em relação ao conteúdo presente em suas plataformas.
Além disso, os cálculos algorítmicos presentes nesses sites contribuem para a formação de bolhas sociais e uma "ilusão de maioria" (LERMAN; YAN; WU, 2016), que é prejudicial à medida que um sujeito ao ver apenas conteúdos com os quais concorda, não questiona suas opiniões e tem a falsa ideia de que o que pensa é uma verdade absoluta. Assim, observamos que os sites de redes sociais não se responsabilizam de maneira alguma em relação ao conteúdo que circula em suas plataformas; criam, no entanto, medidas contra o discurso de ódio pouco efetivas, que abrem brechas para que esses discursos existam livremente, gerando uma permissividade para com o preconceito e a discriminação que são, claramente, um desserviço civilizatório na medida que prejudica, invisibiliza e não reconhece sujeitos que fazem parte de grupos politicamente minoritários. Porém, garantem interações, algo que é de grande interesse para o negócio dos SRS.

Observamos na amostra estudada que o discurso de ódio motivado pelas questões de gênero surge em contextos de midiatização. Nos casos analisados, através da permissividade que os SRS oferecem para esses discursos circulem e das bolhas sociais criadas como consequência dos cálculos algorítmicos, contribui-se para que haja uma disputa de poder entre os sujeitos/consumidores dos conteúdos em questão. Nesses casos, uma opinião é considerada correta e a outra incorreta. Essa 
disputa de poder foi observada até mesmo nos comentários que foram classificados como positivos, visto que dos 3.686 comentários que foram entendidos como positivos na amostra, 279 defendiam a igualdade de gênero de maneira agressiva, com ofensas contra àqueles que não concordavam com esse posicionamento.

Do ponto de vista da ética do reconhecimento, os discursos de ódio de gênero presentes na amostra representam 23\% dos comentários; esses são extremamente antiéticos na medida em que cristalizam ideologias que mobilizam sentidos para a dominação na qual mulheres e sujeitos que não se reconhecem na binariedade de sexo e gênero deveriam ser dominados por homens, brancos, heterossexuais e cisgêneros. Além disso, observamos que até mesmo algumas mulheres (supostamente do sexo feminino, segundo o que pudemos deduzimos de seus perfis) que fazem parte de uma classe socialmente e politicamente oprimida reproduzem o machismo na medida em que estão inseridas dentro do contexto de construção social desse preconceito e, em razão disso, acabam naturalizando-o. Esses discursos também são antiéticos visto que, como mencionado ao longo deste artigo, há a necessidade de uma justiça social que não exija somente estratégias de reconhecimento e representação, mas também estratégias de redistribuição, que pensem as questões materiais derivadas da diferenciação entre classes sociais e gênero como a redistribuição de renda, de recursos e de oportunidades (FRASER, 2007). Logo, consideramos essencial pensar em políticas e medidas que promovam tanto a representação dos sujeitos de grupos politicamente minoritários em razão do gênero quanto o reconhecimento e a redistribuição de recursos para que possam atuar e existir em igualdade na sociedade.

Por fim, cabe recordar que todo discurso possui em si uma dimensão ética. Franklin Leopoldo e Silva (1996) defende que as palavras, além de desempenharem um poder político e simbólico, carregam em si uma dimensão ética que é importante para a construção do indivíduo, da sociedade e também para o autoconhecimento. $O$ mencionado autor ainda deixa claro que a palavra nunca é neutra, uma vez que está impregnada de sentidos, historicidade, usos e significações. Ademais, para Silva (1996) as palavras, através de sua dimensão política podem também ser usadas como uma forma de resistência.

Os discursos, ao estarem impregnados com palavras que julgam, servem ao propósito de afirmar e reafirmar as relações sociais. Dessa maneira, ao proferirmos nossos discursos, escolhemos palavras que ensejam determinado significado. O modo com o qual construímos nossos discursos é revelador não só 
das tramas sociais e culturais às quais pertencemos, mas também revela o nosso "lado", nosso papel social e o lugar que ocupamos nas relações de poder. O discurso de ódio de gênero midiatizado em SRS não escapa a estes pressupostos, razão pela qual analisá-los é uma tarefa de suma importância para a academia, em geral e o campo da comunicação, em particular, denotando à sociedade a relevância de estudos críticos das mídias. Ademais, combatê-los não deixa de ser papel de uma ciência comprometida com a ética, com a justiça social e o bem comum.

\section{Referências}

AMARAL, Adriana. Redes sociais, linguagem e disputas simbólicas. ComCiência, Campinas, n. 131, 2011. Disponível em <http:// comciencia.scielo.br/scielo.php?script $=\mathrm{sci}$ arttext\&pid=S1519-76542011000700009\&lng $=p$ t\&nrm=iso>. Acesso em: $13 \mathrm{dez} .2018$.

BACCEGA, Maria Aparecida. Construindo a cidadania nas interrelações comunicação, educação e consumo. Conexiones, Revista Iberoamericana de Comunicación. v. 2, n. 2, 2010, p. 29-40.

BOURDIEU, Pierre. Poder simbólico. Rio de Janeiro: Bertrand Brasil, 1998.

BOYD, Danah. Social Network Sites as Networked Publics: Affordances, Dynamics, and Implications. In: PAPACHARISSI, Zizi. Networked Self: Identity, Community, and Culture on Social Network Sites. New York: Routledge, 2010. p. 39-58. Disponível em:<http://www.danah.org/papers/2010/
SNSasNetworkedPublics.pdf>. Acesso em: 15 maio 2017.

BRIGGS, Asa. BURKE, Peter. A social history of the media: from Gutenberg to the internet. 2. ed. Cambridge: Polity Press, 2005.

BUTLER, Judith. Problemas de gênero: feminismo e subversão da identidade. Rio de Janeiro: Editora Civilização Brasileira, 2016.

CANCLINI, Néstor García. Consumidores e cidadãos: conflitos multiculturais da globalização. Rio de Janeiro: Editora UFRJ, 2010.

CARLSSON, Ulla. Freedom of Expression and Media in Transition. Studies and reflections in the digital age. Gotemburgo: Nordicom/ University of Gothenburg, 2016.

CASTELLS, Manuel. A internet e a sociedade em rede. In: MORAES, Denis de (Org). Por uma outra comunicação. Rio de Janeiro: Record, 2005. p. 255 a 287.

Communication Power. Oxford:

Oxford University Press, 2009. Redes de indignação e esperança: movimentos sociais na era da internet. Rio de Janeiro: Zahar, 2013.

FRASER, Nacy. Mapeando a imaginação feminista: da redistribuição ao reconhecimento e à representação. Estudos Feministas, Florianópolis, v.15, n. 2, p. 291307, maio/ago. 2007. Disponível em: <https:// periodicos.ufsc.br/index.php/ref/article/view/ So104-026X2007000200002/1781>. Acesso em: 13 dez. 2018.

; HONNET, Axel. ¿Redistribución o reconocimiento?: Un debate político-filosófico. Madri: Ed. Morata, 2006. 
FRAGOSO, Suely; RECUERO, Raquel; AMARAL, Adriana. Métodos de pesquisa para a internet. Porto Alegre: Sulina, 2011. GOMES, Pedro Gilberto. Midiatização: um conceito, múltiplas vozes. Revista Famecos, Porto Alegre, v. 23, n. 2, maio/ jun./jul./ago. 2016. Disponível em: <http:// revistaseletronicas.pucrs.br/ojs/index.php/ revistafamecos/article/view/22253>. Acesso em: 13 dez. 2018.

HERZ, Michael. MOLNAR, Peter. The Content and Context of Hate Speech: Rethinking Regulation and Responses. Cambridge: Cambridge University Press, 2012.

LEAL DA SILVA, Rosane et al. Discursos de ódio em redes sociais: jurisprudência brasileira. Revista Direito-GV, São Paulo, v. 7, n. 2, p. 445-468, jul./dez. 2011. Disponível em: <http://www.scielo.br/scielo.php?script=sci arttext\&pid=S1808-24322011000200004\&lng= en\&nrm=iso >. Acesso em: 13 dez. 2018.

LERMAN, K.; YAN, X.; WU, X-Z. The "Majority Illusion" in Social Networks. PLoS ONE, v. 2, n. 1, 2016. Disponível em: <https://journals. plos.org/plosone/article?id=10.1371/journal. pone.0147617>. Acesso em: 13 dez. 2018.

MAIA, Rousiley. Recognition and the Media. Nova Iorque: Palgrave, 2014.

MONDAL, Anshuman. Islam and Controversy: The Politics of Free Speech After Rushdie. Nova Iorque: Palgrave, 2014.

PEREIRA, Marília Duque Estrada Soares. Éthos em rede: dinâmicas, apropriações e implicações éticas do éthos conectado no Facebook. 2016. 250 f. Dissertação (Mestrado)Programa de Pós-Graduação em Comunicação e Consumo, Escola Superior de Propaganda e Marketing, São Paulo, 2016.
PEREIRA, Gabriela Agostinho. Gênero, ética e discurso: produção, circulação e consumo do discurso de ódio motivado por questões de gênero em sites de redes sociais. 2018. 527 f. Dissertação (Mestrado)-Programa de Pós-Graduação em Comunicação e Consumo, Escola Superior de Propaganda e Marketing, São Paulo, 2018.

PRICE, Monroe. Free expression, globalism, and the new strategic communication. Nova Iorque: Cambridge University Press, 2015.

RECUERO, Raquel. Redes sociais na internet. Porto Alegre: Sulinas, 2014.

SARMENTO, Daniel. A liberdade de expressão e o problema do "Hate Speech". In:

(Org). Livres e iguais: estudos de Direito Constitucional. Rio de Janeiro: Lumen Juris, 2006

\section{SARMENTO, Rayza. Das sufragistas} às ativistas 2.0: feminismo, mídia e política no Brasil (1921 a 2016). 2017. 220 f. Tese (Doutorado em Ciência Política) Universidade Federal de Minas Gerais, Belo Horizonte, 2017.

SILVA, Franklin Leopoldo. A dimensão ética da palavra. Tempo Social, São Paulo, v. 8, n. 2 , p. 53-66, out. 1996. Disponível em: <http:// www.revistas.usp.br/ts/article/view/86295>. Acesso em: 13 dez. 2018.

SILVA, Júlio César Casarin Barroso. Liberdade de Expressão e Expressões de Ódio. Revista Direito GV, São Paulo, v. 11, n. 1, p. 3764, jan./jun. 2015. Disponível em: <http:// bibliotecadigital.fgv.br/ojs/index.php/ revdireitogv/article/view/56785/55322>. Acesso em:13 dez. 2018.

THOMPSON, John B. Ideologia e cultura moderna. Petrópolis: Editora Vozes, 2011. 
WALDRON, Jeremy. The Harm in Hate Speech.

Harvard: Harvard University Press, 2012.

WALKER, Samuel. Hate Speech: The History

of an American Controversy. Nebraska:

University of Nebraska Press, 1994. 


\section{Ethics, freedom of expression and hate speech in social network sites}

\section{Abstract}

Hate speech and gender issues has been shown an interesting topic to debate interaction practices in social network sites. This paper aims to: a) to understand what is gender hate speech and its mediatization; $b$ ) to analyze how is made the production, circulation and consumption of this discourse; and c) to discuss the limits on freedom of expression and the defense of democratic values. For the empiric fieldwork we centered our attention on Facebook, Instagram, Twitter and YouTube. John B. Thompson's deep hermeneutic was used as theoretical and methodological approach. We identify, in the analyzed corpus, four types of gender hate speech (chauvinist, denialist, homo/transphobic and religious) and that, also in these spaces, the mediatization of gender hate speech is perceived as simple opinion, without an ethical character and transvestite as freedom of expression.

\section{Keywords}

Hate speech. Ethics. Gender.

Freedom of expression.

\section{Ética, libertad de expresión y el discurso de ódio en los sites de redes sociales}

\section{Resumen}

El discurso del odio y las cuestiones de género representan una temática interesante para debatir las prácticas de interacción en los sitios de redes sociales. Este artículo tiene como objetivo: a) comprender qué es el discurso de odio de género y su mediatización; b) analizar cómo se realiza la producción, circulación y consumo de este discurso; y c) para discutir los límites de la libertad de expresión y la defensa de los valores democráticos. Para el trabajo empírico centramos nuestra atención en Facebook, Instagram, Twitter y YouTube. Empleamos la hermenéutica de profundidad de John B. Thompson como enfoque teórico y metodológico. Identificamos, en el corpus analizado, cuatro tipos de discurso de odio de género (machista, negacionista, homo/ transfóbico y religioso) y que, en dichos espacios, la mediatización de los discursos de odio de genero es percibida como simple opinión, desproveída de carácter ético y travestida de libertad de expresión.

\section{Palabras clave}

Discurso del ódio. Ética. Género.

Libertad de expresión.

\section{Luiz Peres-Neto}

Doutor e mestre em Ciências da Comunicação pelo Programa de Pós-Graduação em Comunicação do Departamento de Ciências Políticas e Direito Público da Universidad Autónoma de Barcelona, Barcelona, Espanha. Professor do Programa de Pós-Graduação em Comunicação e Práticas de Consumo da Escola Superior de Propaganda e Marketing - ESPM, São Paulo, São Paulo, Brasil. | E-mail: luiz.peres@espm.br ORCID: https://orcid.org/0000-0001-8190-8720

\section{Gabriela Agostinho Pereira}

Mestra em Comunicação e Práticas de Consumo pelo Programa de Pós-Graduação em Comunicação e Práticas de Consumo da Escola Superior de Propaganda e Marketing -ESPM, São Paulo, São Paulo, Brasil. | E-mail: gaapereeira@gmail.com ORCID: https://orcid.org/000-0002-3343-0053

\section{Contribuição dos autores} Concepção e desenho do estudo: Luiz Peres Neto e Gabriela Agostinho Pereira Aquisição, análise ou interpretação dos dados: Luiz Peres Neto e Gabriela Agostinho Pereira Redação do manuscrito: Luiz Peres Neto e Gabriela Agostinho Pereira

Revisão crítica do conteúdo intelectual: Luiz Peres Neto e Gabriela Agostinho Pereira 